Research Article

\title{
Characteristics of the South China Sea Monsoon from the Onset to Withdrawal before and after 1993/94
}

\author{
Zhao Xiaofang $\mathbb{D}^{1,2}$ and Wang Lijuan $\mathbb{D}^{1}$ \\ ${ }^{1}$ Key Laboratory of Meteorological Disaster, Ministry Education, \\ Joint International Research Laboratory of Climate and Environment Change, \\ Collaborative Innovation Center on Forecast and Evaluation of Meteorological Disasters, \\ Nanjing University of Information Science and Technology, Nanjing 210044, China \\ ${ }^{2}$ Wuhan Regional Climate Center, Wuhan 430074, China \\ Correspondence should be addressed to Wang Lijuan; wljfw@163.com
}

Received 8 April 2020; Revised 21 August 2020; Accepted 3 September 2020; Published 16 September 2020

Academic Editor: Enrico Ferrero

Copyright (C) 2020 Zhao Xiaofang and Wang Lijuan. This is an open access article distributed under the Creative Commons Attribution License, which permits unrestricted use, distribution, and reproduction in any medium, provided the original work is properly cited.

\begin{abstract}
The characteristics and possible impact factors of the South China Sea summer monsoon (SCSSM) evolution from onset to withdrawal before and after 1993/94 are investigated using ERA-Interim, CPC rainfall, and OLR data. During the late-onset period of 1979-1993, the SCSSM was characterized by stronger onset intensity and a gradual withdrawal, resulting in a continuous, strong preflood season in Southern China and a slower rain-belt retreat from north to south China in September. In addition, the rain-belt in the Yangtze River basin persisted much longer during summer. However, during the early-onset period in 1994-2016, the SCSSM is associated with a weaker onset intensity and comparatively faster retreat. The advanced preflood season lasted intermittently throughout May and the whole eastern China precipitation lasted until October when it retreated rapidly, making the rain-belt in Southern China persist for an extended duration. Further analysis indicates that a strong modulation of SCS intraseasonal oscillation (ISO) on the SCSSM evolution is observed. There are two active low-frequency oscillations over the SCS in summer during the late-onset period but three during the early-onset period. The wet ISO in the Northwest Pacific propagating northwestward into the SCS and enhanced SCSSM ISO activity may contribute to the early onset and faster withdrawal after 1993/94. The effect of warm western Pacific sea surface temperatures (SST) on the SCSSM evolution is also discussed.
\end{abstract}

\section{Introduction}

Asian monsoons are one of the main energy and moisture sources of the global atmosphere [1]. The SCSSM has a significant position in the Asian monsoon, forming a vital link between the East Asian and South Asian summer monsoons [2-4]. Climatologically, the SCSSM onset is generally accompanied by a continuous eastward retreat of the western North Pacific (WNP) subtropical high, convection enhancement, and the reversal of low-level zonal wind in the SCS $[5,6]$. The synoptic-scale circulation systems, the disturbance of mid-latitude, and the ISO activities can trigger SCSSM onset [7-15]. In addition, the sea surface temperature anomaly (SSTA) is closely related to the interannual variability of the SCSSM onset. A warm (cold) El Niño-Southern Oscillation (ENSO) event in the previous winter and the warm (cold) tropical Indian Ocean (TIO) in the spring can delay (advance) the SCSSM onset [16-19].

There are fewer studies that focus on SCSSM withdrawal when compared to the SCSSM onset [20]. Hu et al. [21] found that SCSSM withdrawal mainly occurred due to the westward intrusion of the WNP subtropical high, which is accompanied by the retreat of the weakening low-level intertropical convergence zone (ITCZ) and rain-belt in the SCS-WNP. The factors contributing to the interannual variability of the SCSSM withdrawal may include tropical cyclones (TCs) and ISO [22]. Luo and Lin [23] suggested that El Niño can delay the monsoon onset and advance the 
SCSSM withdrawal, thus shortening the length of the summer monsoon season.

Recent research has shown that the SCSSM onset date has advanced by about two weeks since 1994 [24-29]. Kajikawa and Wang [25] suggested that the enhanced northwestward intraseasonal variability (ISV) and TC activity from WNP could be responsible for the interdecadal change in the SCSSM onset. Xiang and Wang [30] indicated that the interdecadal advance of the Asian summer monsoon onset may be attributed to a grand La Niña-like pattern change in the Pacific, while that in the South China Sea (SCS) is primarily determined by the abrupt SST warming near the Philippine Sea. Liu et al. [31] highlighted the impact of southern Indian Ocean (SIO) on the SCSSM onset advancement after 1993. Many efforts have been made to understand the cause driving interdecadal change of the SCSSM onset, and interdecadal change in the SCSSM withdrawal after the mid-2000 has been found recently [32]. Considering the integrity of SCSSM evolution, particularly from onset to withdrawal, the following questions can be raised: (1) What changes have happened in the SCSSM evolution from onset to withdrawal since 1993? (2) Previous studies have highlighted the role of SSTA and ISO during this advanced SCSSM onset. What are the effects of ISO and SSTAs on the SCSSM evolution from onset to withdrawal in different periods? These questions will be answered in this paper.

\section{Data and Methods}

The datasets used in this paper include (1) the daily mean interpolated outgoing longwave radiation (OLR) data from the National Oceanic and Atmospheric Administration (NOAA) satellite with resolution of $2.5^{\circ}$ latitude by $2.5^{\circ}$ longitude from 1979 to 2016; (2) the daily mean ECMWF Interim Re-Analysis dataset (ERA-Interim) with resolution of $2.5^{\circ}$ latitude by $2.5^{\circ}$ longitude from 1979 to 2016 (the variables used in this paper include temperature and threedimensional wind fields); (3) the monthly mean Hadley Centre sea surface temperature (SST) dataset for the period of 1979-2016 [33]; and (4) daily precipitation set from the CPC Unified Precipitation Project which is underway at NOAA Climate Prediction Centre (CPC).

In the present study, the SCSSM onset is identified by the seasonal transition of the mid- to upper-tropospheric meridional temperature gradient $(\mathrm{MTG}, \partial \bar{T} / \partial y)$ from winter to summer, which is defined by Mao et al. [34] and Liu et al. [31]. Specifically, the timing of the SCSSM onset is defined by the moment when the pentadly area-averaged MTG in the mid-to-upper troposphere $(500-200 \mathrm{hPa})$ changes from negative to positive and remains positive for at least three pentads over the SCS $\left(10-20^{\circ} \mathrm{N}, 110-120^{\circ} \mathrm{E}\right)$. Then the first pentad from negative to positive phase is defined as the onset of the SCSSM. They suggest that MTG between $500 \mathrm{hPa}$ and $200 \mathrm{hPa}$ is more abrupt in assessing monsoon onset and consistent with the main climatological characteristics of the SCSSM onset, such as area-averaged zonal wind shear reversal, zonal wind reversal, and convection enhancement. There are 72 pentads per year. However, the $850 \mathrm{hPa}$ zonal wind and convection are the two common and significant indices for identifying the SCSSM onset $[21,35]$. In order to take low-level features for a more comprehensive consideration into account the, we corrected the onset date by combining circulation and the onset date defined by the National Climate Centre. The National Climate Centre defines the SCSSM onset by the first pentad when $850 \mathrm{hPa}$ zonal wind in the SCS changes to westerly wind for two constant pentads stably and the average potential pseudoequivalent temperature is greater than $340 \mathrm{~K}$. As a result, we corrected the onset date of 1982, 1997, 2000, 2008, and 2009. The SCSSM withdrawal pentad for 1979-2016 is also defined by MTG. The MTG-defined SCSSM onset and withdrawal originate from thermal differences between north and south, which is the essence of monsoon formation. In order to extract the more obvious signal caused by the SCSSM interdecadal transition, the years with later than average onset are regarded as the typical late-onset years during 1979-1993, which are 1981, 1982, 1985, 1987, 1991, and 1993. The years with an earlier than average onset are regarded as the typical early-onset years during 1994-2016, which are 1994, 1996, 2000, 2001, 2002, 2005, 2006, 2008, 2012, 2013, and 2014.

\section{The Decadal Shift of the SCSSM before and after 1993/94}

3.1. Difference of the SCSSM Onset Characteristics during the Two Epochs. To show the reliability of the MTG-defined SCSSM, the time series of the SCSSM onset date is plotted in Figure 1, which shows a significant advancement of the SCSSM onset date after 1993/1994 and the SCSSM onset time we defined is basically consistent with that defined by the National Climate Centre and its correlation is 0.58. The mean SCSSM onset occurs in about pentad 29 during 1979-1993, while during 1994-2016 it occurs in about pentad 27. The change is about two pentads and the standard deviation (STD) of the SCSSM onset time is 1.67. This interdecadal change of the onset date is consistent with previous studies [24-26] and passes the sliding $t$-test (not shown). Based on the interdecadal change of SCSSM onset, the circulation and convection differences during the SCSSM onset should be researched further.

Figure 2 shows the composite OLR and $850 \mathrm{hPa}$ winds of the SCSSM onset from before and after the onset pentad in each epoch. Lower OLR corresponds to heavy rainfall and strong convection. In the late-onset years of 1979-1993, before the SCSSM onset pentad (Figure 2(a)), a weak anticyclone is centered over the SCS, which makes the SCS be controlled by easterly wind. The active convection area is mainly located in the Bay of Bengal and Indochina Peninsula, extending to the south of China and the south of Japan. When the SCSSM onsets (Figure 2(b)), the developing convection from the Bay of Bengal expands to the northern part of the SCS along with weakening convection over the southern Indian Ocean, indicating that the ITCZ stretched northwards [25]. Southwesterly wind from the Bay of Bengal reaches the SCS resulting in the anticyclone of the Northwest Pacific retreating eastward. After the onset (Figure 2(c)), the 


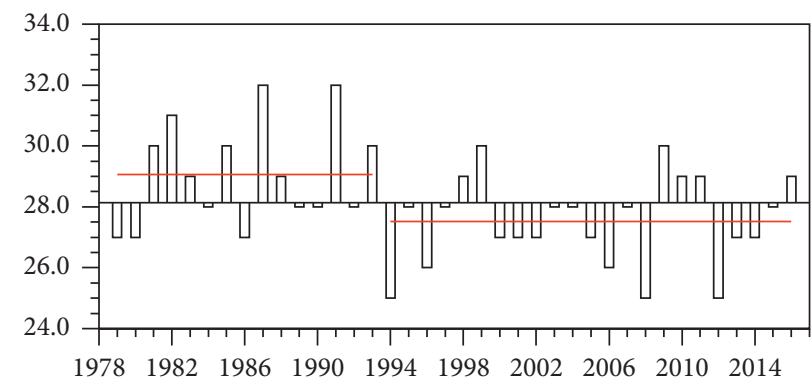

Figure 1: Time series of the MTG-defined SCSSM onset date with the red line denoting the mean epoch date.

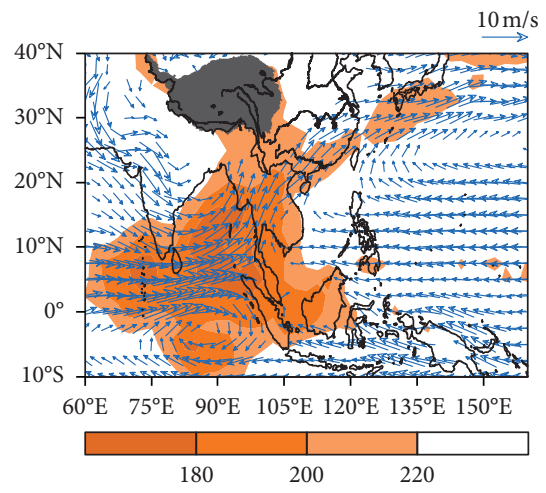

(a)

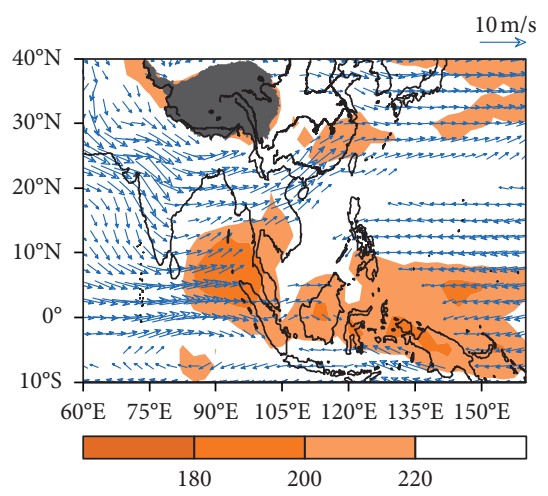

(d)

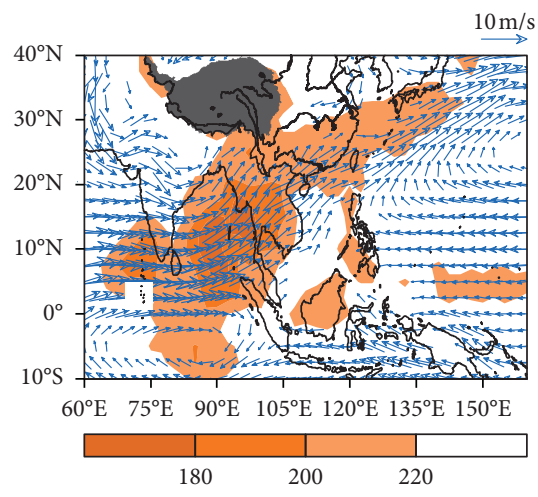

(b)

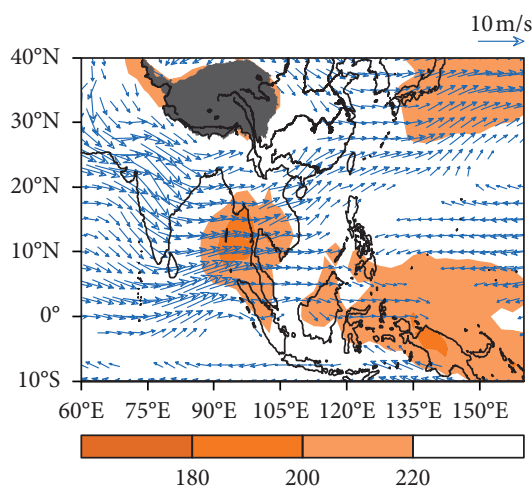

(e)

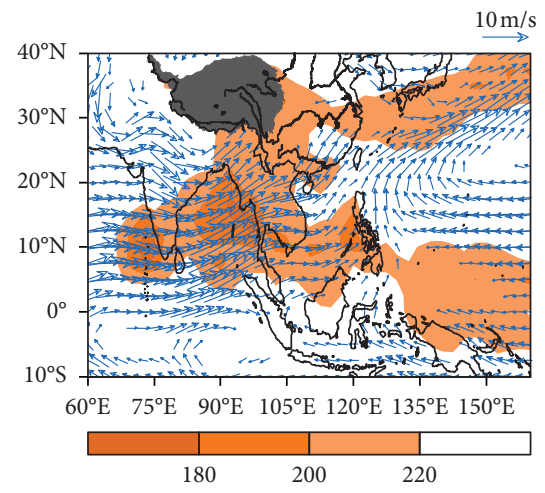

(c)

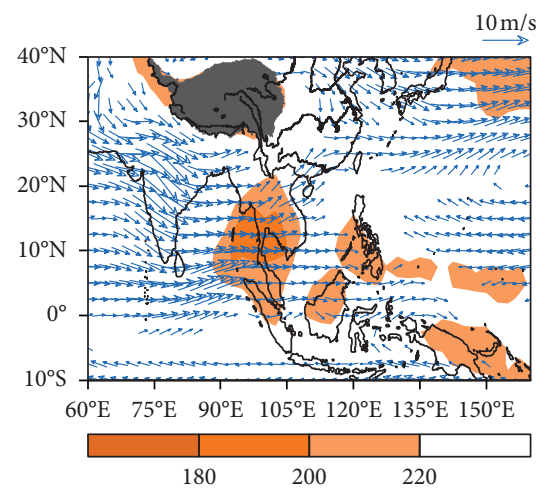

(f)

FIGURe 2: Composite evolution of OLR (W/ $\mathrm{m}^{2}$, shadings) and $850 \mathrm{hPa}$ wind (m/s, vectors) based on the SCSSM onset date in a typical year of the epoch 1979-93 (Top) and 1994-2016 (Bottom) from (a,d) one pentad before the monsoon onset $(P-1)$, (b, e) during the monsoon onset $(P 0)$, and $(c, f)$ one pentad after the monsoon onset $(P+1)$.

active convection over the Arabian Sea and Indochina Peninsula is expanded into the SCS. The convection in the Bay of Bengal is significantly stronger than that in 1994-2016 and the southwesterly wind in the SCS is more intense.

In early-onset years of 1994-2016, the convection in the eastern equator of Indian Ocean is weaker than that in 1979-1993, before the onset pentad (Figure 2(d)). Another distinct convection area is over the Indonesian Maritime Continent. This convection is associated with tropical disturbances, such as easterly wave and MJO, which are favorable for the onset of the SCSSM [22]. When the SCSSM builds up (Figure 2(e)), both active convection over the
Indonesian Maritime Continent and the eastern equator of Indian Ocean are expanded northward. The wind direction over the SCS abruptly changes to westerly direction. After the onset (Figure 2(f)), the convection over the Indonesian Maritime Continent moves northward to the Philippines and enters south of the SCS, but the southwesterly wind in the SCS weakens.

According to the above analysis, the convection source favoring monsoon onset has changed since 1993/94. In addition, it is clearly shown that the reversal and increment of low-level wind in SCS are more noticeable during 1979-1993 when the SCSSM onset is delayed. Figure 3(a) 


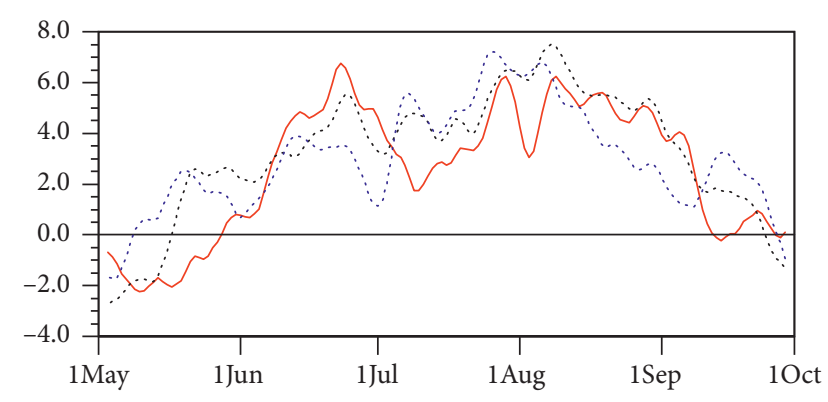

(a)

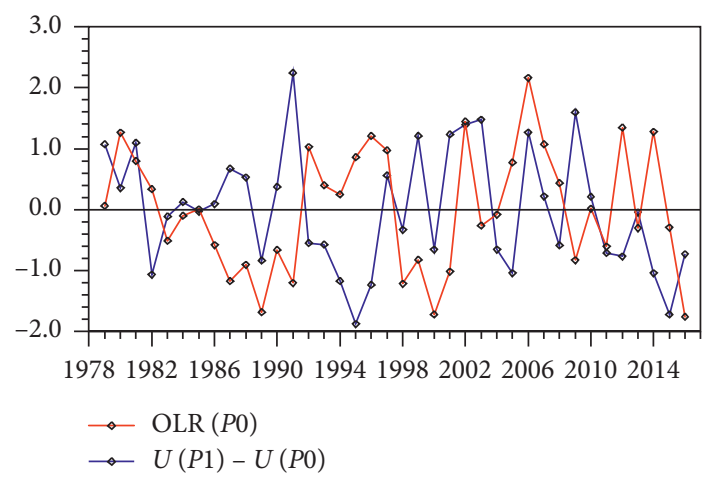

(b)

Figure 3: (a) Time series of 5-day running mean $850 \mathrm{hPa}$ zonal wind $(\mathrm{m} / \mathrm{s})$ averaged over the South China Sea $\left(110^{\circ}-120^{\circ} \mathrm{E}, 10^{\circ}-20^{\circ} \mathrm{N}\right)$. The black, red, and blue curves are climatological years, typical late-onset years during 1979-1993, and typical early-onset years during 1994-2016, respectively. (b) Time series of the standardized OLR (red; W/m $\mathrm{m}^{2}$ ) in the onset pentad and zonal wind growth intensity $(U(P 1)-$ $U(P 0)$; blue; $\mathrm{m} / \mathrm{s})$ over the SCS $\left(110^{\circ}-120^{\circ} \mathrm{E}, 10^{\circ}-20^{\circ} \mathrm{N}\right)$ from 1979 to 2016 .

shows the composite $850 \mathrm{hPa}$ zonal wind evolution over the SCS for typical years and climatology. In 1979-1993, the monsoon builds up late, corresponding to the zonal wind turning positive late. On the other hand, the zonal wind growth is peaking faster in late June. However, in 1994-2016, the monsoon builds earlier; the zonal wind turns positive in early May and grows slowly. The first peak is in mid-June. Thus, what is the relationship between monsoon onset date and intensity?

Due to the change of the zonal wind in the SCS, we expressed the zonal wind growth intensity by zonal wind over the SCS after the SCSSM onset pentad minus the SCSSM onset pentad, which objectively depicts the abrupt onset intensity of SCSSM. Time series of standardized OLR in onset pentad and zonal wind growth intensity in the SCS shows that positive zonal wind growth intensity generally corresponds to negative OLR (Figure 3(b)). This means that a strong zonal wind intensity increase in the SCS generally corresponds to an enhanced convection. Therefore, the convection and wind field in the SCS have obvious coupling characteristics. They show that the SCSSM onset process is a combination of dynamic and thermal. To reveal the relationship between the SCSSM onset date and intensity, we calculated the correlation coefficients between the regional averaged OLR and the zonal wind growth intensity with the SCSSM onset date in the period of 1979-1993 as well as in the period of 1979-2016 (Table 1). The SCSSM onset date is significantly related to the SCSSM onset intensity. There is a positive correlation between the zonal wind growth intensity and the onset date of SCSSM, and there is a negative correlation between the OLR and the onset date of SCSSM. However, the correlation coefficient of two variations during 1994-2016 is much higher and exceeds the 0.01 confidence level, while that during the 1979-1993 epoch fails in passing the 0.05 confidence level and this phenomenon is more obvious during 1994-2016. However, different from $\mathrm{Hu}$ et al. [20] and Torrence and Webster [36], sliding correlation between the SCSSM onset date with OLR and zonal wind growth intensity shows no significant interdecadal shift in
TABLE 1: Correlation coefficients between the anomalies of the zonal wind growth intensity $(U(P 1)-U(P 0))$ and OLR over the SCS in onset pentad and the SCSSM onset dates in the periods of 1979-93 and 1994-2016, respectively.

\begin{tabular}{ccc}
\hline & $U(P 1)-U(P 0)$ & OLR $(P 0)$ \\
\hline $1979-1993$ & 0.23 & -0.25 \\
$1994-2016$ & $0.38^{*}$ & $-0.43^{*}$ \\
$1979-2016$ & $0.36^{* *}$ & $-0.38^{* *}$ \\
\hline
\end{tabular}

Values exceeding the $95 \%$ and $99 \%$ confidence levels are marked by a single or double asterisk $(*$ and $* *)$, respectively.

the relationship between zonal wind growth intensity and OLR in the mid-1990s. This result illustrates that the late onset of the SCSSM is likely to correspond to a strengthened zonal wind and enhanced convection activity, which means that the SCSSM onset intensity is stronger. Therefore, the later (earlier) the SCSSM onset is, the stronger (weaker) the intensity of the SCSSM onset is. Between 1979 and 1993 (1994 and 2016), the SCSSM onset is generally late (early), so the zonal wind growth intensity is stronger (more weakened) and convection is more active (suppressive) in the SCS.

\subsection{Differences of the SCSSM Withdrawal Characteristics} during the Two Epochs. The circulation evolution and abrupt characteristics of the SCSSM onset of the two epochs are discussed above. After the SCSSM onset, the low-level zonal winds appear with a two-peak pattern in summer (Figure 3(a)). In the late-onset years of 1979-1993, the lowlevel zonal wind over the SCS grew rapidly from early June until it reached the first peak, and then it began to decrease. Subsequently, the zonal wind grew again and reached a second peak at the end of July. In the early-onset years of 1994-2016, the zonal wind peaked firstly in mid-June, with a weak intensity. Then, in early July, it started to grow rapidly until the end of July. After summer, what changes have happened to the SCSSM withdrawal since 1993/94?

To find the difference in SCSSM withdrawal characteristics between the two epochs, we must first figure out the 
climatological circulation evolution of $850 \mathrm{hPa}$ wind and OLR during the SCSSM withdrawal. Figure 4 shows the latitudinal-time and longitudinal-time cross section of lowlevel wind and OLR averaged from August 15 to the end of October. Different from the abrupt features of the SCSSM onset, it takes longer for the SCSSM to withdraw. The southwesterly wind and convection retreat from the SCS do not occur simultaneously during the SCSSM withdrawal. Meridionally, the southwesterly wind retreats completely from the northern SCS to the southern SCS in mid-September, while the convection retreats gradually from the SCS until mid-October (Figure 4(a)). Different times for the wind and convection to retreat to the SCS can also be seen in the zonal variation (Figure 4(b)). This nonsimultaneous retreat of westerlies and convection in the SCS is due to the activities of TCs and the synoptic systems embedded in the basic flow of easterly winds, which can contribute to the active convection around the SCS [21]. However, the TC and other synoptic scale systems are also greatly modulated by the WNP anticyclonic/cyclonic anomalies [35], which are closely related to the SCSSM withdrawal. Therefore, it is necessary to consider the progressive retreat convection in the process of SCSSM withdrawal, especially in the determination of the SCSSM retreat date.

According to the above analysis, we use pentadly areaaveraged MTG in the mid-to-upper troposphere $(500-200 \mathrm{hPa})$ when it changes from positive to negative to calculate the date of the SCSSM withdrawal. Considering the inconsistency of convection and wind field retreat during the SCSSM withdrawal, the persistence of MTG turning negative cannot be maintained for three continuous pentads; therefore, the large-scale circulations such as wind field and convection are also taken into account and every pentad in which the MTG changes from positive to negative from September is checked and corrected. Figure 5 shows the time series of the SCSSM withdrawal pentad. The mean and standard deviation (SD) of the SCSSM retreat are pentads 55.3 (about October 8th) and 3.4, while the interannual fluctuation of the SCSSM retreat is stronger than that of the onset, which is consistent with Luo and Lin [23] and Hu et al. [37] who provided two different sets of SCSSM withdrawal dates characteristics. The correlation between the SCSSM withdrawal dates defined by MTG and by Hu et al. [21] is 0.4, which exceeds the $99 \%$ confidence level. We define pentads 53-57 as the withdrawal stages to describe the interannual variability of the SCSSM retreat process. However, the average withdrawal time from 1979 to 1993 is pentad 54.5, while the average withdrawal time from 1994 to 2016 is pentad 55.9. The retreat time was later in the later epoch but it failed to pass the Mann-Kendall test. In Hu et al.'s work [32], there was a significant delay of SCSSM withdrawal between the periods of 1995-2005 and 2006-2016, but the periods in this research were 1979-1993 and 1994-2016. This may be because the study period is different. But the SCSSM withdrawal also exhibits a delay after the mid-2000s if it was defined by our approach. For example, the average SCSSM withdrawal date from 1995 to 2005 was 54.4 pentads, and the average SCSSM withdrawal date from 2006 to 2016 was 57.7 pentads, which is almost consistent with $\mathrm{Hu}$ et al.'s result.
From the composite results, the earlier the SCSSM onset, the later the SCSSM withdrawal after 1993.

Now that the SCSSM withdrawal dates have been defined, we will explore the circulation evolution during the retreat period. Figure 6 shows the climatological compositions of low-level wind and OLR during the SCSSM withdrawal period from 1979 to 2016. It can be seen that active convection is located in the Bay of Bengal to the Northwest Pacific before the SCSSM withdrawal pentad, and it retreats gradually from northeast to southwest (Figures 6(a) and 6(b)) and then completely withdraws from the SCS, since the SCSSM withdrawal pentad and convection centers shift to the Indonesia area (Figures 6(c) and 6(d)). Meanwhile, the low-level wind is already easterly before the SCSSM withdrawal pentad, but it is obvious that the northeasterly wind has become stronger on the SCSSM withdrawal pentad. To further objectively investigate the variability of circulation factors during the SCSSM withdrawal, the pentad-mean of $850 \mathrm{hPa}$ zonal wind and OLR averaged over the SCS evolution are composited in Figure 7. There appears to be a significant decrease in zonal wind and a weakened convection whose value rises remarkably from about $220 \mathrm{~W} / \mathrm{m}^{2}$ to around $240 \mathrm{~W} / \mathrm{m}^{2}$ over the SCS in the SCSSM withdrawal pentad. Zonal wind and convection almost develop at the same time when the SCSSM onsets, but, during the SCSSM retreat, the westerly wind and convection retreat from the SCS do not occur simultaneously [21]. It was zonal wind shifting to easterly wind firstly and then convection retreat from the SCS (Figure 4). The time difference of them is about 20 days. The SCSSM withdrawal dates defined in this paper take into account not only the wind field but also OLR; therefore, the $850 \mathrm{hPa}$ zonal wind in pentad $(-3)$ is already easterly wind. It reveals the "abrupt change" of the SCSSM onset and the "gradual change" of the SCSSM retreat from the dynamics and thermal structure of atmosphere. Thus, the characteristics of the wind field and convection during the SCSSM withdrawal show that the retreat time defined by MTG is reliable. However, based on the interdecadal change of the SCSSM, what characteristics have changed on the SCSSM withdrawal?

To further study the differences of the SCSSM withdrawal before and after 1993, we composite the anomalies of $850 \mathrm{hPa}$ wind and OLR during the SCSSM withdrawal period for typical years in Figure 8. During the period of 1979-1993, before the SCSSM withdrawal pentad, the lowlevel and convection anomalies are not significant in the SCS (Figure 8(a)). On the SCSSM retreat pentad, an enhanced easterly wind anomaly and increased OLR anomaly, meaning weakened convection, appear over the SCS and subtropical western North Pacific. The easterly wind anomaly and weakened convection extend eastward to the Bay of Bengal (Figures 8(b) and 8(c)). Comparison of the difference before and after the SCSSM withdrawal pentad (Figure 8(d)) shows that the SCSSM withdrawal leads to remarkable increases in easterly wind from the SCS to the Bay of Bengal, as well as an anomalous anticyclone over the western North Pacific, which accompanies a weakened convection over the east of Philippines and east of the SCS. 


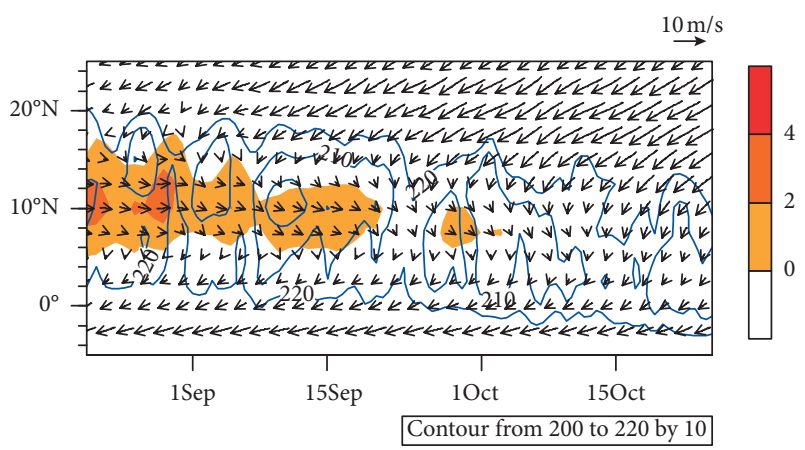

(a)

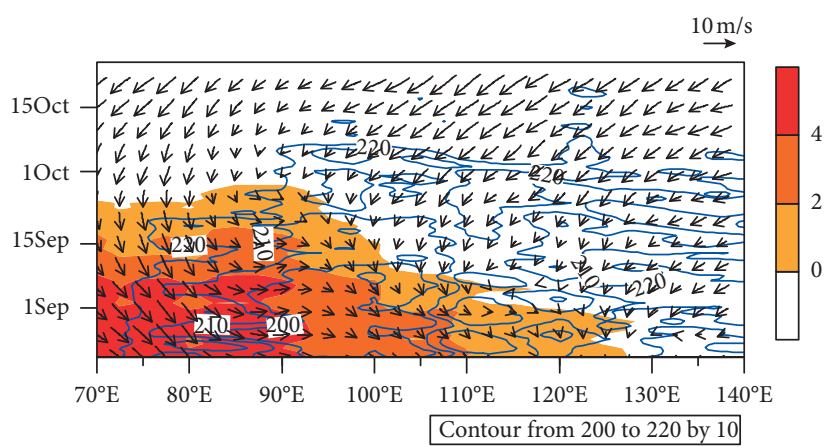

(b)

FIGURE 4: Latitude-time diagram of climatological $850 \mathrm{hPa}$ wind (vector, $\mathrm{m} / \mathrm{s}$ ), southwesterly wind (shading, m/s), and OLR (contour, W/ $\mathrm{m}^{2}$ ) (a) between $110^{\circ} \mathrm{E}$ and $120^{\circ} \mathrm{E}$ and (b) between $10^{\circ} \mathrm{N}$ and $20^{\circ} \mathrm{N}$. The vector unit is $10 \mathrm{~m} / \mathrm{s}$ and the shading and contour interval is $10 \mathrm{~W} / \mathrm{m}^{2}$.

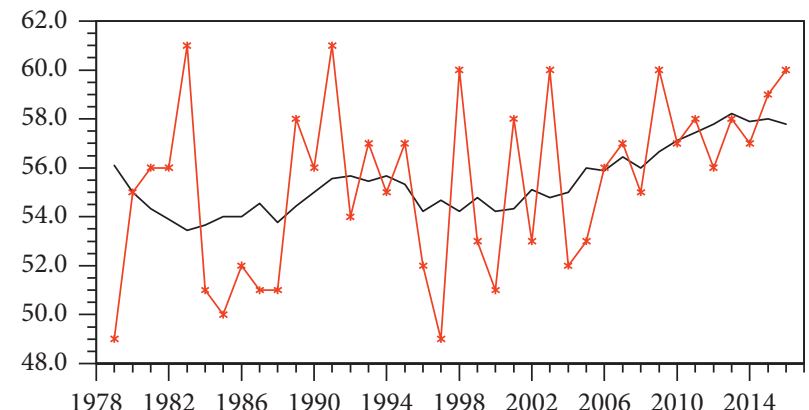

Figure 5: The pentad of the SCSSM withdrawal dates (red line). The black lines denote the 5-year running average.

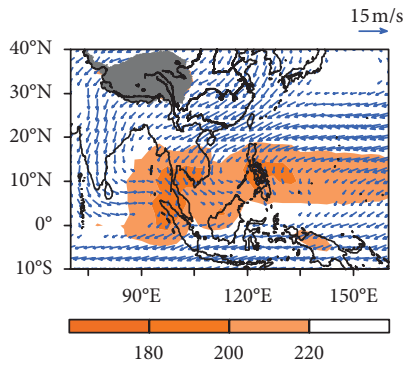

(a)

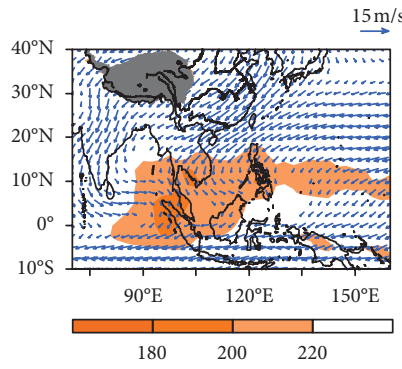

(b)

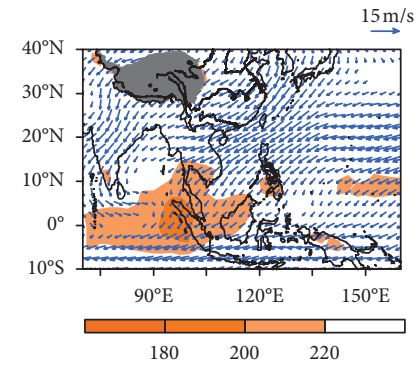

(c)

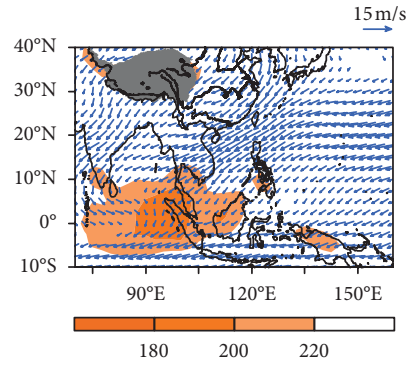

(d)

FIGURE 6: Composite evolution of OLR (W/ $/ \mathrm{m}^{2}$, shadings) and $850 \mathrm{hPa}$ wind ( $\mathrm{m} / \mathrm{s}$, vectors) based on the SCSSM withdrawal date from (a) two pentads before the monsoon withdrawal $(P-2)$, (b) one pentad before the monsoon withdrawal $(P-1)$, (c) during the monsoon withdrawal $(P 0)$, and $(\mathrm{d})$ one pentad after the monsoon withdrawal $(P+1)$ for the period of 1979-2016.

In the period of 1994-2016, before the SCSSM withdrawal pentad, strong westerly anomalies are found over the Bay of Bengal extending through the South China Sea to the east of the Philippines, which transports abundant warm moisture to favor the active convection over the SCS and Northwest Pacific (Figure 8(e)). On the withdrawal pentad, the low-level wind abruptly transits to a northeasterly anomaly in the SCS and persists into the next pentad, which is stronger than that in the period of 1979-1993. On the other hand, a suppressed convection appears in the SCS and eventually extends eastward to the
Bay of Bengal on the next pentad of the SCSSM withdrawal (Figures 8(f) and 8(g)). Comparing the differences before and after the SCSSM withdrawal pentad, the increased easterly wind in the SCS is sharper than that in the period of 1979-1993, and the convection over the Northwest Pacific, SCS, and the Bay of Bengal is weakened along with the SCSSM withdrawal, which is associated with a southward migration of the seasonal march of the ITCZ (Figure 8(h)). It is suggested that the SCSSM withdrawal rate during the period of 1994-2016 is faster than that of the period of 1979-1993. 


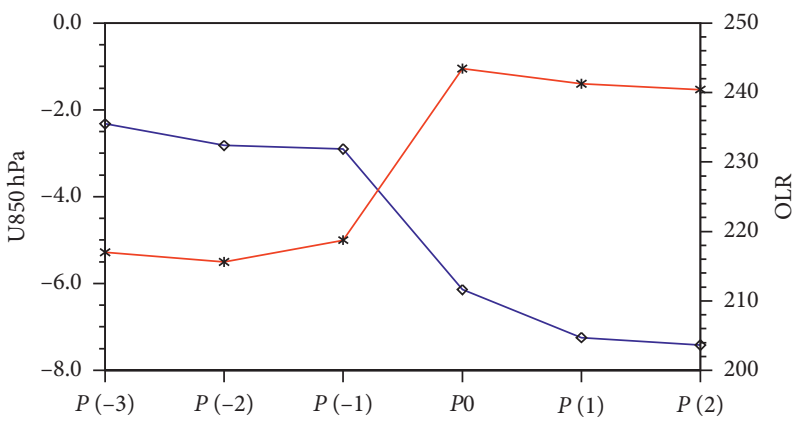

Figure 7: Pentad $850 \mathrm{hPa}$ zonal wind $(\mathrm{m} / \mathrm{S})$ and OLR $\left(\mathrm{W} / \mathrm{m}^{2}\right)$ averaged over the South China Sea $\left(110^{\circ}-120^{\circ} \mathrm{E}, 10^{\circ}-20^{\circ} \mathrm{N}\right)$ from three pentads before the SCSSM withdrawal $(P-3)$ to two pentads after the SCSSM withdrawal $(P+2)$.

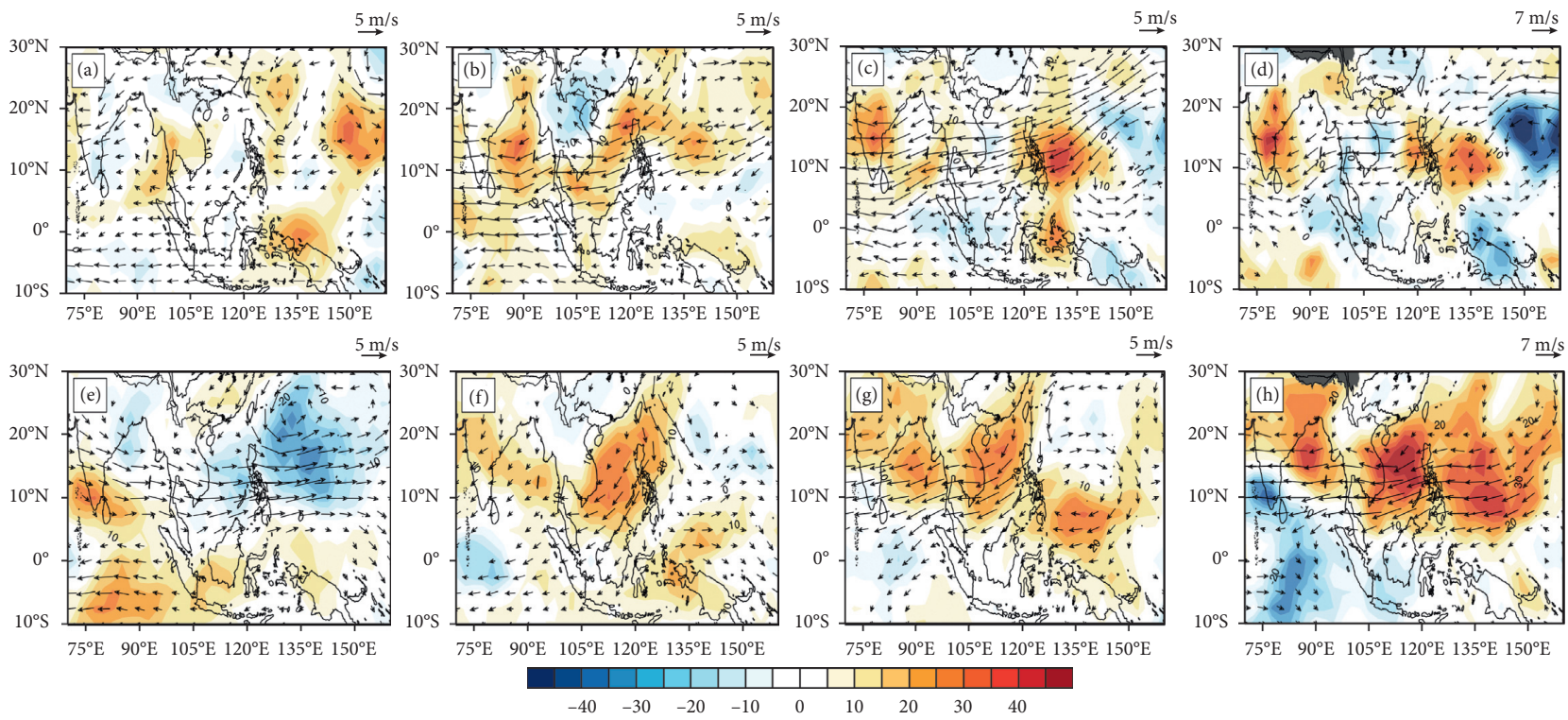

FIGURE 8: Composite differences in OLR (W/ $/ \mathrm{m}^{2}$, shadings) and $850 \mathrm{hPa}$ wind (m/s, vectors) based on th SCSSM withdrawal date in typical years of the epoch 1979-1993: (a) one pentad before the monsoon onset $(P-1)$, (b) during the monsoon onset (P0), (c) one pentad after the monsoon onset $(P+1)$ and the withdrawal stages (pentads 53-37), and (d) differences between after $(P+1)$ and before $(P-1)$ the monsoon withdrawal. $(\mathrm{e}-\mathrm{h})$ the same as $(\mathrm{a}-\mathrm{d})$ but for the epoch 1994-2016.

In short, the distinct characteristics of the SCSSM are that, during the period of 1979-1993 (1994-2016), the SCSSM onset is generally later (earlier) and the intensity of the SCSSM onset is stronger (weaker). On the other hand, there is no obvious difference in the SCSSM retreat date, but the speed of the SCSSM retreat is slower (faster) and the duration is longer (shorter). This raises the following question: what is the effect of this change on rainfall in China?

3.3. Distinct Rainfall Distribution from the Onset to Withdrawal of the SCSSM during the Two Periods. Many previous studies have confirmed that the evolution of the SCSSM has a broad impact on the spatial and temporal distribution of rainfall in East Asia during the period from May to September. Particularly, the SCCSSM onset has been regarded as the beginning of the East Asian rainy season $[12,38-41]$. It is necessary to figure out the link between the different characteristics of the SCSSM in two epochs and the rainfall distribution in Eastern China. Seasonal evolution of latitudinal $\left(110^{\circ}-120^{\circ} \mathrm{E}\right)$ averaged rainfall between two epochs is shown in Figure 9. In the late-onset years of 1979-1993, the maximum rainfall belt $\left(>10 \mathrm{~mm} \cdot \mathrm{day}^{-1}\right)$, corresponding to the first rainy season in Southern China, begins at the end of May (Figure 9(a)). Moreover, for the late-onset period, the SCSSM intensity is stronger, leading to more warm moisture being constantly transported into Southern China. The rainfall persists consistently until the beginning of June until the major rain-belt moves northward to the middle and lower reaches of the Yangtze River basin (around $30^{\circ} \mathrm{N}$ ), which is associated with the Meiyu front. By the end of July, the maximum rainfall belt moves over Southern China again, which can be regarded as the beginning of the last flood season in Southern China. The rainfall in Eastern China reduces from $35^{\circ} \mathrm{N}$ north to $25^{\circ} \mathrm{N}$ south from early September to early October. 


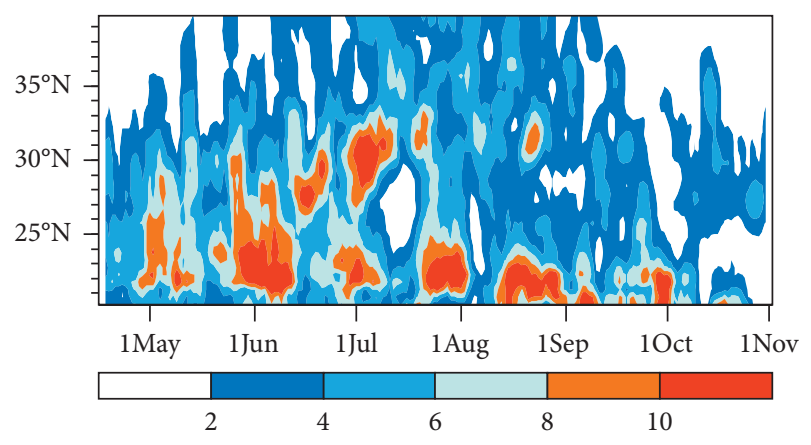

(a)

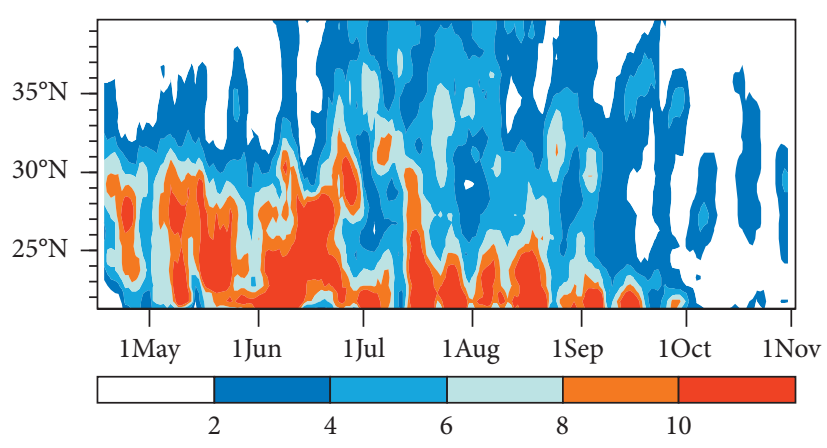

(b)

FIGURE 9: Latitude-time cross sections of 5-day running mean precipitation (mm/day) averaged between $110^{\circ} \mathrm{E}$ and $120^{\circ} \mathrm{E}$ in typical years of the epoch: (a) 1979-93 and (b) 1994-2016.

In the period of 1994-2016, the SCSSM onset is generally early. The first rainy season in South China begins at the beginning of May and continues intermittently to the end of June until the major rain-belt moves northward to the middle and lower reaches of the Yangtze River basin (Figure 9(b)). The Meiyu period during 1994-2016 is shorter than that during 1979-1993. By mid-July, the maximum rainfall belt moves to the Southern China again and it decreases with Eastern China rainfall simultaneously from late September to early October, consistent with the faster and shorter retreat of the SCSSM. On the other hand, the two migrations of the rain-belt are closely related to the two-peak pattern of the zonal wind over the SCS in summer, which is consistent with previous studies [42].

\section{Effects of ISO on the SCSSM Evolution from Onset to Withdrawal during the Two Periods}

The above analyses have shown different characteristics of the SCSSM from onset to withdrawal before and after 1993/94 and the effect of the SCSSM change on rainfall distribution. Thus, a question to be further addressed is, what are the mechanisms responsible for this characteristic change? Several studies have discussed the importance of two dominant modes of ISOs on the triggers of the SCSSM onset and withdrawal [43-46]. It is found that 10-25-day and 30-80-day oscillations also control the SCSSM activity from May when the SCSSM onsets to October when the SCSSM retreats through power spectrum analysis (fig. not shown). To detect the effects of ISO on the SCSSM evolution from onset to withdrawal during the two epochs, we calculated standard deviations of the 10-25- and 30-80-day filtered OLR from 15 May to 15 October, which cover the 5 months from climatological SCSSM onset to withdrawal. Figure 10 shows the differences (1994-2016 to 1979-1993) of mean standard deviation between the two epochs. The difference of the 30-80-day oscillation mode over the SCS is significant and the strength of the 30-80-day oscillations is large in the SCS during the period of 1994-2016. Thus, the effect of 30-80-day ISO on the SCSSM evolution during the two periods will be studied further.

To explore the 30-80-day ISO activities of the SCSSM, an East Asian summer monsoon index $\left(I_{\mathrm{M}}\right)$, which is proposed by Mao and Chan [44], has been applied. That is, $I_{M}=\left(\left(v_{\mathrm{SW}}-\overline{v_{\mathrm{SW}}}\right) / \sigma_{v}-(R-\bar{R})\right) / \sigma_{R}$, where $v_{\mathrm{SW}}=(u+v) /$ $\sqrt{2}, R$ is OLR, $\sigma_{v}$ and $\sigma_{R}$ are the standard deviations of $v_{\mathrm{SW}}$ and OLR, respectively, and $\overline{v_{\mathrm{SW}}}$ and $\bar{R}$ are the multiyear averages of $v_{\mathrm{SW}}$ and OLR, respectively. The advantage of this index is that it takes into account the dynamic and thermodynamic characteristics of the monsoon. In this study, the 30-80-day band-pass filtering of $I_{M}$ over the SCS $\left(110^{\circ}-120^{\circ} \mathrm{E}, 10^{\circ}-20^{\circ} \mathrm{N}\right)$ is applied as the daily ISO index of the SCSSM. Figure 11 shows the typical daily ISO evolution from April to November in the SCS between two epochs. A strong modulation of SCS ISOs on the SCSSM evolution is observed. In the late-onset period of 1979-1993, the SCS ISO has been in a dry phase, postponing the monsoon onset due to low-frequency easterly wind anomalies and weakening convection until late May. The ISO then turns to the positive phase and develops to the maximum amplitude of the whole monsoon period. The low-frequency convection and westerly wind are significantly strengthened and favor a strong SCSSM onset. The transformation time is very near pentad 29 (May 26-31). There are two active low-frequency oscillations in summer, namely, "South China Sea monsoon surge," which has been discussed in depth by Li et al. [46], corresponding to the two rain-belt migrations. After September, the ISO gradually weakened and disappeared, corresponding to the weakening and slowing retreat of the SCSSM.

In the early-onset years of 1994-2016, the ISO of the SCSSM turns to the positive phase around the beginning of May. The first positive peak value of ISO is smaller than that in the period of 1979-1993, corresponding to a weaker SCSSM onset intensity. Then there are three active lowfrequency oscillations from June to September, with stable amplitude. In early October, the ISO transforms rapidly to the negative phase, contributing to the shorter, faster retreat of the SCSSM. It is inferred that the 30-80-day ISO was crucial for the SCSSM from onset to withdrawal between two epochs.

We have made a preliminary analysis for the effect of local SCS 30-80-day ISO on the SCSSM evolution difference; how does each ISO propagate and where is the ISO propagation source? Figure 12 shows the zonal and meridional 


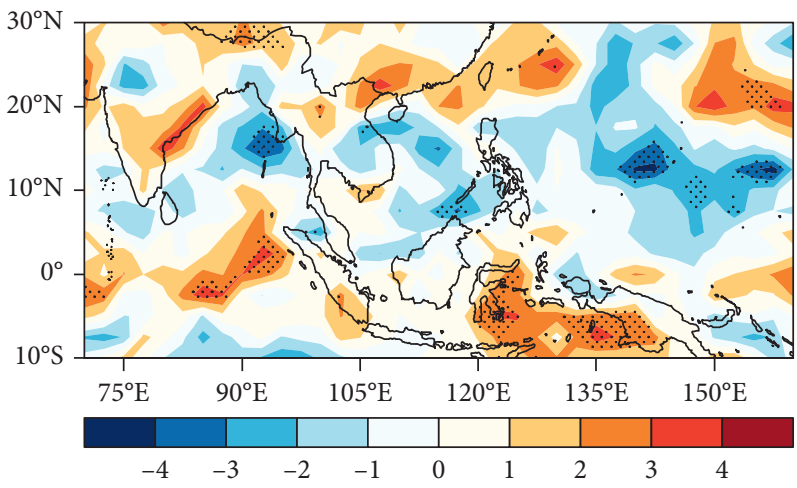

(a)

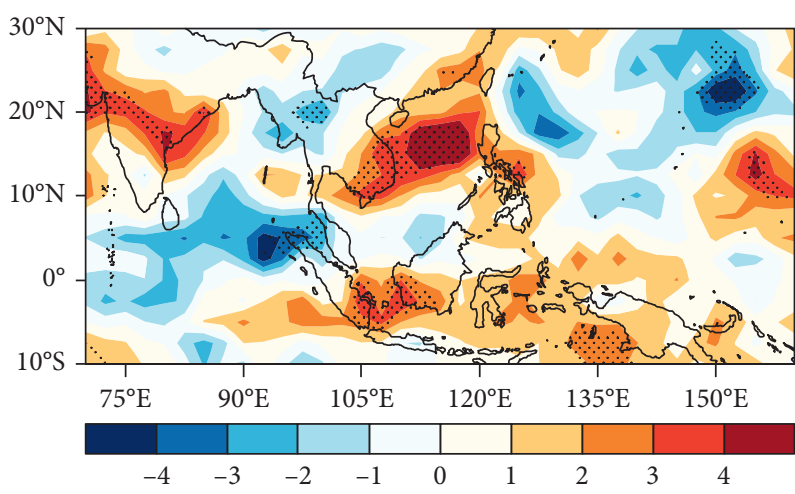

(b)

Figure 10: Difference in the Lanczos filtered OLR anomalies in (a) 10-25-day and (b) 30-80-day time scales from 15 May to 15 October between 1994-2016 and 1979-1993. Units are in W/m² and the dotted areas denote that the differences are significant at the $95 \%$ confidence level.

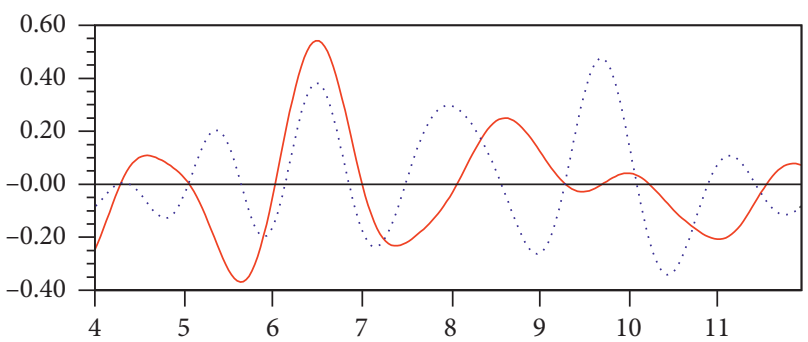

FIgure 11: Composite daily ISO index evolution from April to November over the SCS. Red line is in a typical year of the epoch 1979-93, and blue dots are in a typical year of the epoch 1994-2016.

propagation of ISO along with $10^{\circ}-20^{\circ} \mathrm{N}$ and $110^{\circ}-120^{\circ} \mathrm{E}$ during the two periods. In the period of 1979-1993, the wet ISO propagates eastward from tropical Indian Ocean to the SCS along with $10^{\circ}-20^{\circ} \mathrm{N}$ in early June and mid-August (Figure 12(c)). Moreover, when ISO activity in the Indian Ocean is relatively strong, the propagation to the SCS is also strong. In meridional direction, the positive ISO propagates northward into the SCS. In September, there is ISO propagating from Indian Ocean but not entering the SCS. Different from the late-onset period, in the period of 1994-2016, the first two wet ISOs propagate westward from the Northwest Pacific in May and June, and the last two propagate eastward from the Indian Ocean in July and September. In zonal direction, the ISOs also propagate northward into the SCS. Therefore, the wet ISO in the Northwest Pacific propagating northwestward into the SCS may contribute to the SCSSM evolution difference after 1993/94 and the SCSSM ISO intensity can be predicted by monitoring ISO anomalies over the northwest Pacific and Indian oceans.

\section{Effects of SSTAs on the SCSSM Evolution from Onset to Withdrawal during the Two Periods}

In addition to the effects of internal atmospheric dynamic mechanism, SST, an important external force, also plays an important role in the SCSSM evolution. Previous studies have discovered that the delayed onset of SCSSM may result from a La Niña event [47]. The early onset and delayed retreat of the SCSSM can be ascribed to warm SST anomalies in the Philippine Sea [23, 30]. A warm SST in the tropical Indian Ocean during the previous winter [19] can delay the SCSSM onset by suppressing the convection over the western Pacific. It is also interesting to find that the spatial pattern of the SST evolution exhibits specific interdecadal characteristics during two periods. As shown in Figure 13 on the left, significant positive SST anomalies appear around the equatorial Eastern Pacific in the late-onset years of the period of 1979-1993 in May and continue developing until November. Meanwhile, the spatial pattern of the SST changes is similar to the horseshoe-shaped SST warming during El Niño events. In theory, the warm tropical eastern Pacific SST anomaly may induce an anticyclone anomaly in the northwest Pacific due to the excitation of ascending Rossby waves. This anticyclone anomaly connects to the low-level easterly anomaly in the SCS, which possibly postpones the onset of SCSSM [48]. In the early-onset years of the period of 1994-2016, significant warm SST anomalies appear in the Philippine Sea from April to September, and the strongest warm SST appears in May and then gradually weakens. A few weak negative SST anomalies appear around the equatorial Eastern Pacific (Figure 13 on the right). Thus, the SST warming in the Philippine Sea from April to September may be a crucial external force for the SCSSM evolution in the period of 1994-2016. However, a deeper understanding of the mechanism of this SST change on the SCSSM evolution during two epochs calls for further study.

\section{Summary and Discussion}

In this study, we investigate the different characteristics and possible impact factors of the SCSSM evolution from onset to withdrawal before and after 1993/94 when an interdecadal change occurs. The results suggest that, during the period of 1979-1993, the SCSSM onsets later, corresponding to abrupt enhancement of zonal wind and convection activity, results in a stronger SCSSM onset intensity. Delayed onset also 


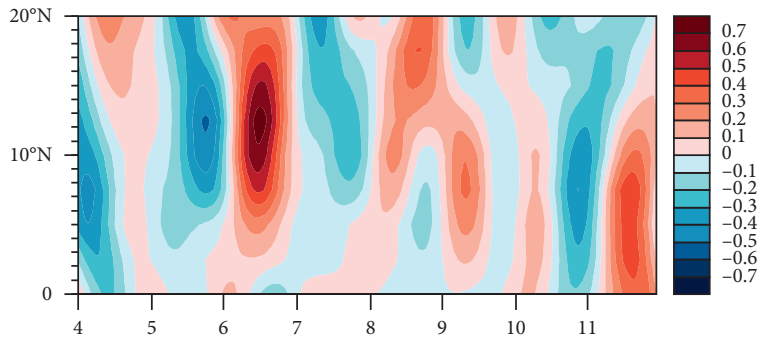

(a)

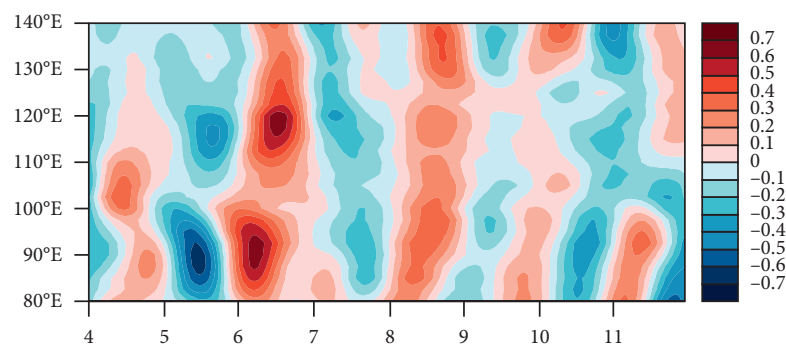

(c)

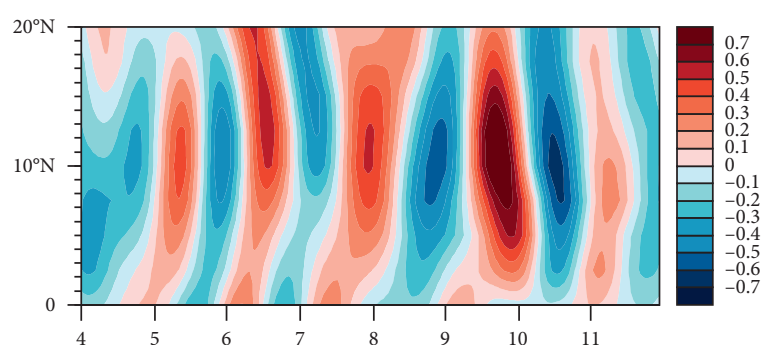

(b)

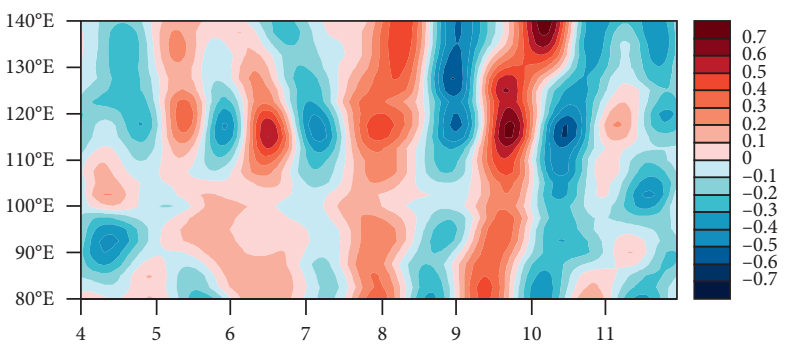

(d)

FIgURE 12: Latitude-time (left) and longitude-time (right) diagram of the daily SCSSM ISO propagation from April to November between ((a) and (c)) late-onset years of the period of 1979-1993 and ((b) and (d)) early-onset years of the period of 1994-2016.

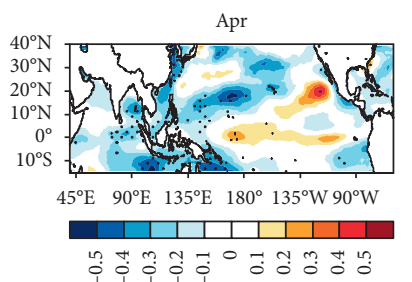

(a)

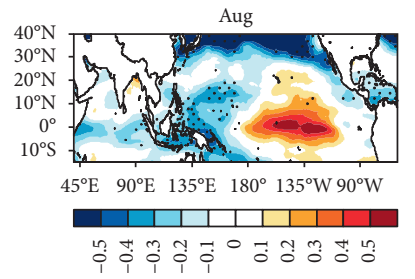

(e)

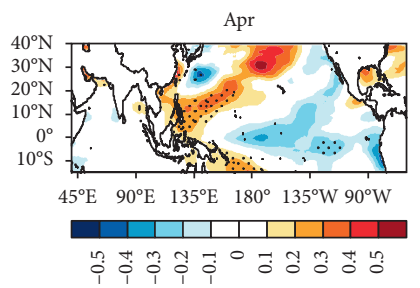

(i)

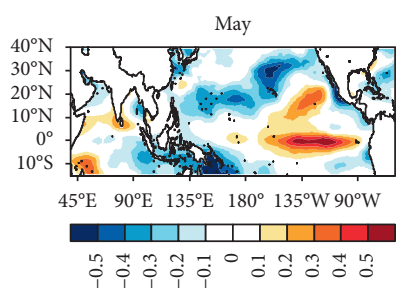

(b)

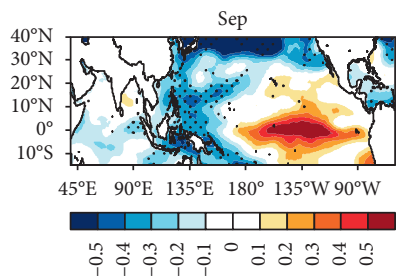

(f)

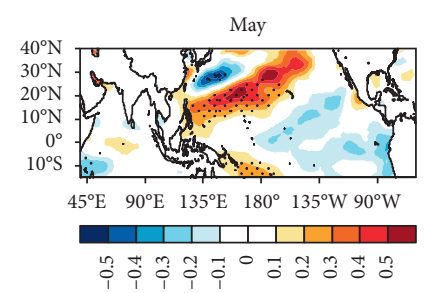

(j)

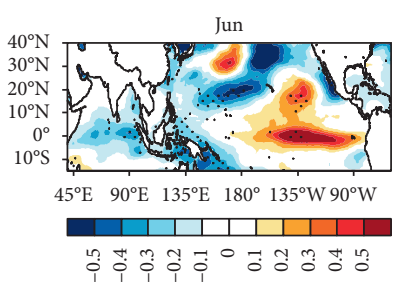

(c)

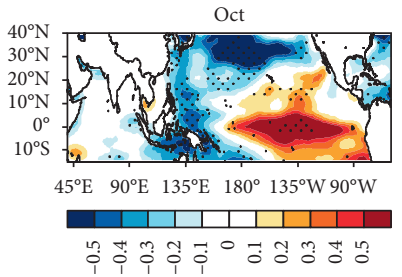

(g)

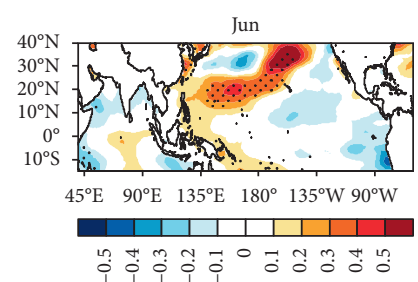

(k)

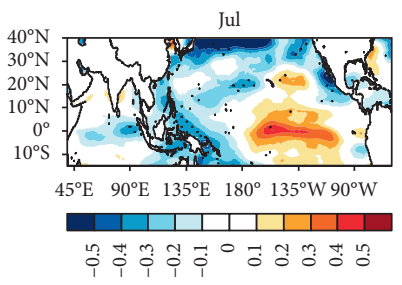

(d)

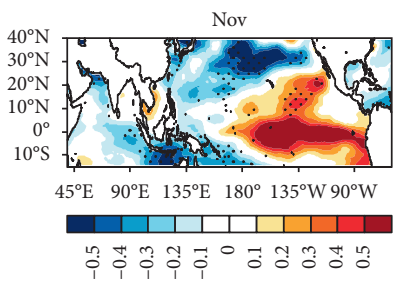

(h)

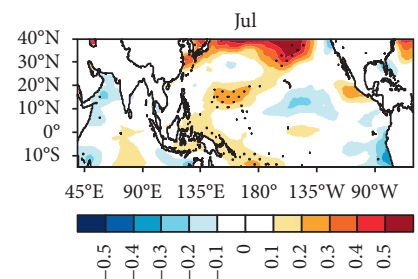

(l)

Figure 13: Continued. 


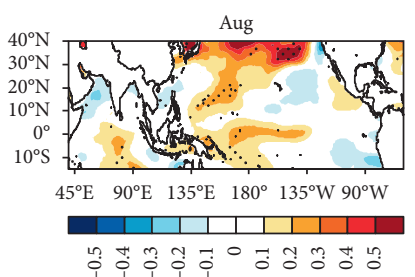

(m)

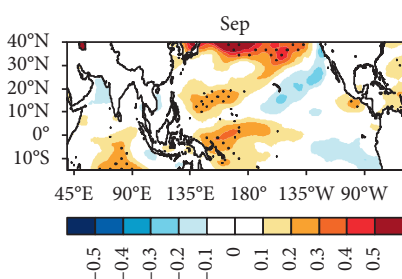

(n)

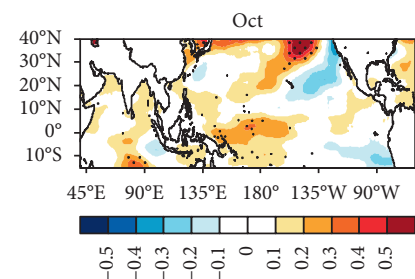

(o)

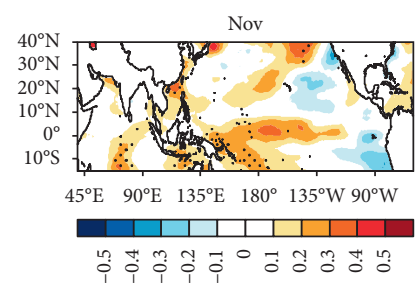

(p)

FIgURE 13: Composite monthly SSTAs (shading; (K)) from April to November between late-onset years of the period of 1979-1993 (left) and early-onset years of the period of 1994-2016 (right). Thick solid lines surround the region exceeding the $90 \%$ confidence level, respectively. (a, i) Apr, (b, j) May, (c, k) Jun, (d, l) Jul, (e, m) Aug, (f, n) Sep, (g, o) Oct, and (h, p) Nov.

results in a continuous, strong rain-belt appearing in Southern China at the end of May. After the SCSSM onset, the low-level zonal winds appear with a two-peak pattern in summer, and two abrupt increases of the zonal winds correspond to the beginning of the Meiyu period in Yangtze River valley and the last flood season in Southern China, respectively. The monsoon retreats from September until October and exhibits an extended, gradual retreat, which causes the withdrawal of the rain-belt to begin in September from north to south China and completely vacate at the beginning of October.

However, after 1993/94, the SCSSM onsets earlier and is characterized by a weaker onset intensity and more rapid retreat. The preflood season advanced and lasted intermittently throughout May. The rain-belt in Southern China persisted for a longer time in summer. The monsoon started to retreat from October, resulting in the rapid retreat of the rain-belt from the whole eastern China.

Further analyses indicate that the enhanced 30-80-day SCS ISO activities are an important contributor for SCSSM evolution change. There are two active low-frequency oscillations over the SCS in summer during the late-onset period but three ISOs in the early-onset period. Prior to 1993/94, the SCS ISO had been in a dry phase, which postponed the monsoon onset until late May. Then a late and strong onset is triggered by enhanced wet ISO propagating northeastward from the equatorial Indian Ocean. After September, the ISO gradually weakened and disappeared, corresponding to the weakening and slowing retreat of the SCSSM. After 1993/94, the wet ISO from the Northwest Pacific propagated northwestward to the SCS in early May, which modulated the mid-May onset of SCSSM. After October, the SCS ISO transformed rapidly to the negative phase, contributing to the shorter duration and faster retreat of the SCSSM.

Moreover, the distinct SCSSM evolution is closely related to the SST change. Significantly positive SST anomalies appear around the equatorial Eastern Pacific in the lateonset years of the period of 1979-1993 in May and continue developing until November. The spatial patterns of the SST changes are similar to the horseshoe-shaped SST warming during El Niño events. However, in the early-onset years of the period of 1994-2016, warm SST anomalies appear in the Philippine Sea from April to September. Many researchers have noted the effect of ENSO-related western North Pacific
SST and Philippine Sea temperature on the SCSSM onset in May and withdrawal in September [30, 32, 49]. The specific physical mechanism for the impact of SST on the monsoon evolution from May to September should thus be studied further. On the other hand, air-sea interaction can provide an additional northward propagation mechanism for 30-60day Northwest Pacific ISO and ISO source [50]. The influence of SSTAs on the SCSSM ISO should also be studied as it may provide a basis for predicting the subsequent SCSSM evolution.

\section{Data Availability}

Daily precipitation data and OLR were derived from https:// www.esrl.noaa.gov/psd/data/gridded/. The HadISST data were from http://www.metoffice.gov.uk/hadobs/hadisst/ data/download.html. The ERA-Interim data were obtained from https://apps.ecmwf.int/datasets/data/interim-full-daily/ levtype $=\mathrm{pl} /$.

\section{Conflicts of Interest}

The authors declare that they have no conflicts of interest.

\section{Acknowledgments}

This research was jointly supported by the National Key R\&D Program of China (2019YFC1510004) and the National Natural Science Foundation of China (41975085).

\section{References}

[1] X. Shao, P. Huang, and R. H. Huang, "A review of the south China sea summer monsoon onset," Advances in Earth Science, vol. 29, no. 10, pp. 1126-1137, 2014, in Chinese.

[2] S. Y. Tao, "A review of recent research on the east asian summer monsoon in china," Monsoon Meteorology, pp. 6092, Oxford University Press, Oxford, UK, 1987.

[3] B. Wang, Y. Zhang, and M.-M. Lu, "Definition of south China sea monsoon onset and commencement of the east Asia summer monsoon," Journal of Climate, vol. 17, no. 4, pp. 699-710, 2004.

[4] Y. Ding and C. He, "The summer monsoon onset over the tropical eastern Indian Ocean: the earliest onset process of the Asian summer monsoon," Advances in Atmospheric Sciences, vol. 23, no. 6, pp. 940-950, 2006. 
[5] L. J. Wang, "Abrupt changes in elements around the 1998 SCS summer monsoon establishment with analysis of its characteristic process," Transactions of Atmospheric Sciences, vol. 22, no. 2, pp. 135-140, 1999, in Chinese.

[6] J. H. He, "Large scale features of SCS summer monsoon onset and its possible mechanism," Climatic and Environmental Research, vol. 5, no. 4, pp. 333-334, 2000.

[7] J. Mao and G. Wu, "Influences of Typhoon Chanchu on the 2006 south China sea summer monsoon onset," Geophysical Research Letters, vol. 35, no. 12, 2008.

[8] H. Zheng and Z. Wen, "The western pacific tropical vortex and the onset of the south China sea summer monsoon in 2001," Journal of Tropical Meteorology, vol. 25, no. 4, pp. 119-124, 2009.

[9] A. Lin, D. Gu, and C. Li, "Impact of equatorial MJO activity on summer monsoon onset in the south China sea," Chinese Journal of Geophysics, vol. 59, no. 1, pp. 28-44, 2016.

[10] J.-Y. Lee, B. Wang, M. C. Wheeler, X. Fu, D. E. Waliser, and I.-S. Kang, "Real-time multivariate indices for the boreal summer intraseasonal oscillation over the Asian summer monsoon region," Climate Dynamics, vol. 40, no. 1-2, pp. 493-509, 2013.

[11] Y. Fu and Y. Liu, "Onset and the evolution of the summer monsoon over the south China sea during SCSMEX field experiment in 1998," Journal of the Meteorological Society of Japan, vol. 79, no. 1, pp. 255-276, 2001.

[12] Y. Ding and J. C. L. Chan, "The east Asian summer monsoon: an overview," Meteorology and Atmospheric Physics, vol. 89, no. 1, pp. 117-142, 2005.

[13] A. L. Lin and C. H. Li, "Relationship between onset of the south China sea summer monsoon and south China frontal precipitation in the first raining period on climatological mean," Acta Scientiarums Naturalium Universitatis Sunyatseni, vol. 49, no. 4, pp. 134-143, 2010, in Chinese.

[14] D. Yihui, C. Li, and L. Yanju, "Overview of the south China sea monsoon experiment," Advances in Atmospheric Sciences, vol. 21, no. 3, pp. 343-360, 2004.

[15] H. Wang, B. F. Liu, and T. Li, "Effects of intraseasonal oscillation on south China sea summer monsoon onset," Climate Dynamics, vol. 51, no. 7-8, pp. 2543-2558, 2018.

[16] P. J. Webster and S. Yang, "Monsoon and ENSO: selectively interactive systems," Quarterly Journal of the Royal Meteorological Society, vol. 118, no. 507, pp. 877-926, 1992.

[17] J. Ju and J. Slingo, "The Asian summer monsoon and ENSO," Quarterly Journal of the Royal Meteorological Society, vol. 121, no. 525, pp. 1133-1168, 1995.

[18] Z. Liang, Z. Wen, and L. Wu, "The relationship between the Indian Ocean sea surface temperature anomaly and the onset of south China sea summer monsoon I: coupling analysis," Chinese Journal of Atmospheric Sciences, vol. 30, no. 4, pp. 619-634, 2006.

[19] Y. Yuan, "Impacts of the basin-wide Indian Ocean SSTA on the south China sea summer monsoon onset," International Journal of Climatology, vol. 28, no. 22, pp. 1579-1587, 2008.

[20] P. Hu, W. Chen, and R. D. Huang, "On the weakening relationship between the south China sea summer monsoon onset and cross-equatorial flow after the late 1990s," International Journal of Climatology, vol. 38, no. 7, pp. 3202-3208, 2018.

[21] P. Hu, W. Chen, H. Ruping, and P. Nath, "Climatological characteristics of the synoptic changes accompanying south China sea summer monsoon withdrawal," International Journal of Climatology, vol. 39, no. 2, pp. 1-17, 2018.
[22] P. Hu, W. Chen, and H. Ruping, "Interannual variability and triggers of the south China sea summer monsoon withdrawal," Climate Dynamics, vol. 53, no. 22, pp. 1-18, 2019.

[23] M. Luo and L. Lin, "Objective determination of the onset and withdrawal of the south China sea summer monsoon," Atmospheric Science Letters, vol. 18, no. 6, pp. 276-282, 2017.

[24] Y. Kajikawa, T. Yasunari, S. Yoshida, and H. Fujinami, "Advanced Asian summer monsoon onset in recent decades," Geophysical Research Letters, vol. 39, no. 3, 2012.

[25] Y. Kajikawa and B. Wang, "Interdecadal change of the south China sea summer monsoon onset," Journal of Climate, vol. 25, no. 9, pp. 3207-3218, 2012.

[26] F. Yuan and W. Chen, "Roles of the tropical convective activities over different regions in the earlier onset of the south China sea summer monsoon after 1993," Theoretical and Applied Climatology, vol. 113, no. 1-2, pp. 175-185, 2013.

[27] J. Feng and D. Hu, "How much does heat content of the western tropical Pacific Ocean modulate the south China sea summer monsoon onset in the last four decades?" Journal of Geophysical Research: Oceans, vol. 119, no. 7, pp. 4029-4044, 2014.

[28] G. Chen, "Comments on interdecadal change of the south China sea summer monsoon onset"” Journal of Climate, vol. 28, no. 22, pp. 9029-9035, 2015.

[29] B. Wang and Y. Kajikawa, "Reply to "comments on interdecadal change of the south China sea summer monsoon onset"” Journal of Climate, vol. 28, no. 22, pp. 9036-9039, 2015.

[30] B. Xiang and B. Wang, "Mechanisms for the advanced Asian summer monsoon onset since the mid-to-late 1990s," Journal of Climate, vol. 26, no. 6, pp. 1993-2009, 2013.

[31] B. Liu, C. Zhu, Y. Yuan, and K. Xu, “Two types of interannual variability of South China Sea summer monsoon onset related to the SST anomalies before and after 1993/94," Journal of Climate, vol. 29, no. 19, pp. 6957-6971, 2016.

[32] P. Hu, W. Chen, and S. Chen, "Interdecadal change in the south China sea summer monsoon withdrawal around the mid-2000s," Climate Dynamics, vol. 52, no. 9-10, pp. 6053-6064, 2019.

[33] N. A. Rayner, D. E. Parker, E. B. Horton et al., "Global analyses of sea surface temperature, sea ice, and night marine air temperature since the late nineteenth century," Journal of Geophysical Research, vol. 108, no. D14, p. 4407, 2003.

[34] J. Mao, J. C. L. Chan, and G. Wu, "Relationship between the onset of the south China sea summer monsoon and the structure of the Asian subtropical anticyclone," Journal of the Meteorological Society of Japan, vol. 82, no. 3, pp. 845-859, 2004.

[35] G. M. Martin, A. Chevuturi, R. E. Comer, N. J. Dunstone, A. A. Scaife, and D. Zhang, "Predictability of south China sea summer monsoon onset," Advances in Atmospheric Sciences, vol. 36, no. 3, pp. 253-260, 2019.

[36] C. Torrence and P. J. Webster, "Interdecadal changes in the ENSO-monsoon system," Journal of Climate, vol. 12, no. 8, pp. 2679-2690, 1999.

[37] P. Hu, W. Chen, S. Chen, and R. Huang, "Statistical analysis of the impacts of intra-seasonal oscillations on the south China sea summer monsoon withdrawal," International Journal of Climatology, vol. 40, no. 3, pp. 1919-1927, 2020.

[38] J. He and Z. Zhu, "The relation of south China sea monsoon onset with the subsequent rainfall over the subtropical east Asia," International Journal of Climatology, vol. 35, no. 15, pp. 4547-4556, 2015. 
[39] Y. H. Ding, "Summer monsoon rainfalls in China," Journal of the Meteorological Society of Japan, vol. 70, no. 1, pp. 337-396, 1992.

[40] L. Wu, R. Huang, H. He, Y. Shao, and Z. Wen, "Synoptic characteristics of heavy rainfall events in pre-monsoon season in south China," Advances in Atmospheric Sciences, vol. 27, no. 2, pp. 315-327, 2010.

[41] S. Yao, Q. Tong, and T. Li, "The 10-30-day oscillation of winter rainfall in southern China and its relationship with circulation patterns in different latitudes," International Journal of Climatology, 2019.

[42] Q. Wang and Y. H. Ding, "Climatological aspects of evolution of summer monsoon over the northern south China sea," ActaMeteorologicaSinica, vol. 55, no. 4, pp. 466-483, 1997, in Chinese.

[43] B. Zheng, A. Lin, and C. Li, "The northward propagation and mechanisms of the intraseasonal oscillation of south China sea summer monsoon in 2007," Journal of Tropical Meteorology, vol. 27, no. 6, pp. 869-876, 2011.

[44] J. Mao and J. C. L. Chan, "Intraseasonal variability of the south China sea summer monsoon," Journal of Climate, vol. 18, no. 13, pp. 2388-2401, 2005.

[45] H. W. Tong, J. C. L. Chan, and W. Zhou, "The role of MJO and mid-latitude fronts in the south China sea summer monsoon onset," Climate Dynamics, vol. 33, no. 6, pp. 827-841, 2009.

[46] T. Li, X. Yang, and J. Ju, "Intraseasonal oscillation features of the south China sea summer monsoon and its response to abnormal Madden and Julian Oscillation in the tropical Indian Ocean," Science China Earth Sciences, vol. 56, no. 5, pp. 866-877, 2013.

[47] J. H. Ju, C. Qian, and J. Cao, "The intraseasonal oscillation of east Asian summer monsoon," Chinese Journal of Atmospheric Science, vol. 29, no. 2, pp. 23-30, 2005, in Chinese.

[48] Z. Wen and J. Liang, "The abnormal characteristics of tropical SST and its influence on the onset of the SCS summer monsoon," in Proceedings of the 26th Annual Session of CMA, Paper Collection of the Venue of Monsoon Vynamics, Beijing, China, 2009.

[49] R. Zhang, A. Sumi, and M. Kimoto, "A diagnostic study of the impact of El Niño on the precipitation in China," Advances in Atmospheric Sciences, vol. 16, no. 2, pp. 229-241, 1999.

[50] T. Wang, X.-Q. Yang, J. Fang, X. Sun, and X. Ren, "Role of airsea interaction in the 30-60-day boreal summer intraseasonal oscillation over the western north Pacific," Journal of Climate, vol. 31, no. 4, pp. 1653-1680, 2018. 